\title{
Anesthesia and Surgical Microvascular Flaps
}

\author{
Cláudia Margarida Brito Pereira ${ }^{1}$, Maria Eduarda Leite Figueiredo ${ }^{2}$, Rita Carvalho ${ }^{2}$, Dora Catre ${ }^{3}$, \\ José Pedro Assunção 4
}

\begin{abstract}
Summary: Pereira CMB, Figueiredo MEL, Carvalho R, Catre D, Assunção JP - Anesthesia and Surgical Microvascular Flaps.
Background and objectives: Head and neck reconstructive surgery represents a major challenge facing the need to achieve a good cosmetic and functional outcome. Anesthesia may be an important and determining factor in the technique success due to its role in hemodynamic stability and regional blood flow. On the other hand, regional anesthesia, changes in blood volume, and vasoactive drugs may influence blood flow in the flap. Thus, due to the lack of recommendations based on evidence, the anesthetic technique of these procedures is most often inspired in pathophysiological considerations. The aim of this paper is to review relevant aspects regarding anesthetic practice in these cases.
\end{abstract}

Content: Importance of the type of surgical flap, physiological considerations, and anesthetic approach.

Conclusions: In surgery with microvascular flaps, the anesthesiologist role includes optimizing the physiological conditions for the survival of the flap without increasing the non-surgical morbidity.

Keywords: Anesthesia; Surgical Flaps; Vascular Surgical Procedures.

@2012 Elsevier Editora Ltda. All rights reserved.

\section{INTRODUCTION}

Head and neck reconstructive surgery represents a major challenge facing the need to achieve a good cosmetic and functional outcome. Free flaps performed with microanastomoses add to other surgical techniques (healing by second intention, primary closure of the defect, regional or local pedicle skin flaps) a new option in trying to achieve this goal. Since the introduction of free tissue transfer in the ' 60 s, the success rate has improved substantially and is currently $95-99 \%$ among experienced surgeons ${ }^{1}$.

This technique allows free vascularized tissue transplantation using microsurgical techniques ${ }^{2}$ that have the following advantages:

- allows the excision of lesions not previously excisable;

- greater control of the lesion site in the short and long run;

- better functional prognosis;

- possibility of two teams working simultaneously (one responsible for excise the lesion and another for reconstruction);

\footnotetext{
Received from Hospital S. Teotônio - Viseu, Portugal.
}

1. Anesthesiologist; Hospital Assistant of Anesthesiology, Hospital S. Teotônio

2. MD; Intern, Expertise in Anesthesiology, Hospital S. Teotônio

3. Anesthesiologist, Hospital S. Teotônio

4. Anesthesiologist; Director of the Department of Anesthesiology, Hospital S. Teotônio

Submitted on January 28, 2011.

Accepted on September 5, 2011.

Correspondence to:

Cláudia Margarida Brito Pereira, MD

E-mail: eduardaleite@ hotmail.com
- better rate of vascularization and healing;

- low rate of reabsorption;

- size of defect is less important, allowing to expand the safety margins in case of oncologic surgery;

- potential for sensory or motor innervation and use of osseointegrated implants;

- wide variety of available tissues, composite tissues, different tissue types;

- use of grafts designed for the defect and better use of tissue harvested;

- easier for possible immediate reconstruction.

The main disadvantage is the need for trained and experienced surgical team and everyone involved in the follow-up and monitoring of the patient and long operative time required for its accomplishment. The technique limitations are the long duration of the surgery, with high surgical-anesthetic risk and the possibility of comorbidities that may influence the technique success (e.g., diabetes mellitus, poor nutritional status, cardiovascular disease, peripheral vascular disease, collagen diseases) ${ }^{1}$.

In fact, despite improved surgical techniques, hypoperfusion and subsequent flap "failure" remains a concern ${ }^{3}$.

Anesthesia may be an important and determining factor in the technique success due to its role in hemodynamic stability and regional blood flow. On the other hand, regional anesthesia, changes in blood volume, and vasoactive drugs may influence blood flow in the flap 4,5 . Thus, due to the lack of recommendations based on evidence, the anesthetic technique of these procedures is most often inspired in pathophysiological considerations ${ }^{2}$. The aim of this paper is to review relevant aspects regarding anesthetic practice in these cases. 


\section{THE FLAP}

There are two types of flaps:

Pedicle flap - released and twisted around the neurovascular pedicle, and thus without interruption of blood flow (BF);

Free flap - the neurovascular pedicle is removed from the donor site and transplanted by microvascular anastomosis to a new location.

The flaps are therefore used to reconstruct a primary defect, but it gives rise to a secondary defect, which will be repaired by direct suture or skin graft. Examples of surgeries with the use of flaps are hand reconstruction or replantation surgery after traumatic amputation, fractures with bone loss, burns, head and neck neoplastic surgery, and breast reconstructive surgery. Examples of flaps include the forearm (radial and ulnar), latissimus dorsi, and rectus abdominis ${ }^{6}$.

The microvascular technique of free flap and its artery and vein transfer and its anastomosis to the receiver site has several stages: 1) harvesting the flap and clamping vessel, primary ischemia as soon as BF stops and intracellular anaerobic metabolism starts (dependent on surgical time 6090 minutes); 2) reperfusion as soon as arterial and venous anastomosis are complete and after declamping; 3) secondary ischemia, a result of flap hypoperfusion (minimized with appropriate anesthetic approach) ${ }^{6}$.

\section{Primary ischemia}

With $\mathrm{BF}$ cessation, the flap becomes anoxic. In the presence of anaerobic metabolism, lactate accumulates, intracellular $\mathrm{pH}$ decreases, ATP decreases, $\mathrm{Ca}^{2+}$ increases, and there is accumulation of proinflammatory mediators. The severity of the damage caused by primary ischemia is proportional to the duration of ischemia. Tissues with high metabolic rate are more sensitive to ischemia and, therefore, the flap skeletal muscle is more sensitive to ischemia than the skin ${ }^{6}$.

\section{Reperfusion}

Reperfusion begins with vessel declamping. Typically, BF restoration reverses the physiological transient changes triggered by primary ischemia. With minor injuries, the flap recovers and normal metabolism is restored. However, an injury (ischemia/ reperfusion) may occur if some flap factors are unfavorable, namely, prolonged periods of ischemia or inadequate perfusion pressure. In this case, reperfusion injury occurs when BF allows the influx of inflammatory substances that may ultimately destroy the flap ${ }^{6}$.

\section{Secondary ischemia}

Secondary ischemia occurs after flap transfer and reperfusion. This period is more harmful to the flap than primary ischemia. The flaps affected by secondary ischemia present with massive intravascular thrombosis and significant interstitial edema. Although the skin can tolerate up to $10-12 \mathrm{~h}$ of ischemia, after a few hours irreversible pathological changes arise in the muscle ${ }^{6}$.

Free flaps are denervated, suffer a variable period of ischemia (primary ischemia), and lose their intrinsic sympathetic tone. However, both the artery and veins maintain innervation and respond to local, physical, and chemical stimuli (cold and drugs). The absence of intact lymphatic drainage increases the risk of interstitial edema with high sensitivity to fluid leakage and pressure effects.

Blood flow is usually reduced to half the original flow (which may take days or weeks to return to normal) 6 .

\section{Causes of flap failure ${ }^{4}$}

- Arterial: arterial thrombosis, vasospasm.

- Venous drainage: venous thrombosis, vasospasm, mechanical compression (e.g., dressings, positioning).

- Flap edema: excessive use of crystalloids, excessive hemodilution, prolonged ischemia, histamine release (e.g., anesthetics, antibiotics), flap excessive manipulation.

- Generalized vasoconstriction: hypovolemia, hypothermia, pain, respiratory alkalosis (e.g., decreased cardiac output).

- Hypotension: hypovolemia, myocardio depressor drugs (e.g., anesthetics, $\mathrm{Ca}^{2+}$ channel blockers), vasodilation, heart failure (e.g., ischemia, volume overload, acidosis).

- Prolonged ischemia of the flap.

\section{PHYSIOLOGICAL CONSIDERATIONS}

The patient's physiological status has greater influence on flap viability, but anesthetic management and postoperative care also have a direct effect on outcome. Surgery is typically long (6-8h) with multiple sites of tissue trauma, which results in considerable fluid, blood, and heat losses. Hypovolemic vasoconstriction and hypothermia, if not corrected, undermine the flat BF and viability 6 . Even with a good strategy in terms of fluid therapy, the flap BF can decrease $50 \%$ during the first 6-12 hours after surgery.

The guiding principle of anesthesia for microvascularized flap is the maintenance of an adequate $\mathrm{BF}^{6}$.

Assuming that the $\mathrm{BF}$ is laminar, its determinants are defined by the Hagen-Poiseuille equation:

$$
\mathrm{Q}=\Delta \mathrm{Pr}^{4} \varpi / 8 \quad
$$

$\mathrm{Q}$ : laminar flow; $\Delta \mathrm{P}$ : pressure difference at the tube endings; r: radius; : viscosity; l: length of tube. 
Thus, $\mathrm{BF}$ is proportional to the radius of the vessel to the $4^{\text {th }}$ power and inversely proportional to viscosity. Any change in perfusion pressure, viscosity, and vessel diameter will influence $\mathrm{BF}^{6}$.

The practical implication of Hagen-Poiseuille equation for anesthesiologists is that $\mathrm{BF}$ in pedicle and free flap can be optimized while maintaining good perfusion pressure, reducing viscosity and increasing the vessel diameter (vasodilation) ${ }^{7}$.

\section{Perfusion pressure}

Arterial tension is the main determinant for the pressure gradient in transplanted tissue. Adequate anesthetic depth and aggressive fluid resuscitation are usually sufficient. Most inotropic agents are contraindicated due to the vasoconstrictor effects. If necessary, some authors recommend the use of small doses of dobutamine and dopamine ${ }^{6}$.

\section{Viscosity}

Isovolemic hemodilution improves BF by reducing viscosity and muscle reperfusion injury and increasing the number of patent capillaries, which reduces tissue necrosis. There is a nonlinear relationship between viscosity and hematocrit $(\mathrm{Ht})-$ viscosity is greatly increased above the $\mathrm{Ht}$ of $40 \%$. Thus, $\mathrm{Ht}$ of about $30 \%$ appears to be one that offers the best balance between viscosity and $\mathrm{O}_{2}$-carrying capacity. Further reductions in hematocrit did not result in greater benefit, and benefit may even be overcome by the decrease in $\mathrm{O}_{2}$-carrying capacity:

$$
\mathrm{DO}_{2}=\mathrm{CO}(\mathrm{Hb} \times \text { sat } \times 1.34)+\left(\mathrm{PaO}_{2} \times 0.003\right)
$$

A low hematocrit also increases cardiac work, a fact to be considered in patients with low cardiac reserve ${ }^{6}$.

Blood viscosity is influenced by many factors including cold, plasma fibrinogen, and drugs. BF is also influenced by platelet sequestration 7 .

Microvascular surgery activates a procoagulant process. This favors platelet sequestration, which leads to BF stagnation and consequent ischemic necrosis (particularly if the distal portion of flap extends beyond the vascular region of its artery). Muscle and skin can tolerate a few hours of ischemia, but if exposed to primary ischemia, its tolerance is reduced to half when exposed to secondary ischemia (delayed phase in hypoperfusion, which begins after blood circulation is restored) ${ }^{5}$.

\section{Vasodilation}

The vessel's radius is a major determinant for blood flow (either those supplying or present in the flap) ${ }^{6}$.

\section{Temperature}

In addition to vasoconstriction, hypothermia is also responsible for increased viscosity and hematocrit, platelet and red blood cells aggregation, which can reduce the microcirculation in the flap. Thus, the patient should be kept warm in the operating room, ICU, and the first 24 to 48 hours. This can be achieved by increasing the room temperature and using forced air heater. Active heating should start before the onset of anesthesia, as the patient rapidly cools after induction ${ }^{6}$.

\section{Fluid therapy}

Peripheral vasoconstriction due to an underestimation of fluid losses is common. Insensitive losses of fluid and blood affect both the donor and receiver sites, also favored by raising the temperature. Mild hypervolemia reduces sympathetic vascular tone and dilates the flap vessels. An increase of $2 \mathrm{~cm} \mathrm{H}_{2} \mathrm{O}$ in central venous pressure (CVP) above the baseline can double the cardiac output and produces skin and muscle vasodilatation ${ }^{6}$.

\section{Crystalloids}

- $\quad 10-20 \mathrm{~mL} \cdot \mathrm{kg}^{-1}$ (preoperative deficit replacement)

- $4-8 \mathrm{~mL} \cdot \mathrm{kg}^{-1} \cdot \mathrm{h}^{-1}$ to replace perioperative insensible losses

\section{Colloids}

- $10-15 \mathrm{~mL} . \mathrm{kg}^{-1}$ for hemodilution

- For blood loss replacement

$$
\begin{aligned}
& \text { Blood } \\
& \text { - To maintain hematocrit } \pm 30 \% \\
& \text { Dextrans } \\
& \text { - Often administered postoperatively }
\end{aligned}
$$

\section{Anesthesia}

Some studies suggest that isoflurane has the advantage over other compounds and propofol of producing vasodilation with minimal cardiac depression. Propofol inhibits platelet aggregation that can reduce the risk of thrombosis (effect of intralipid on platelet-erythrocyte interaction/increased synthesis of nitric oxide by leukocytes) ${ }^{6}$. Literature reports no advantage in any of the techniques.

\section{Vasospasm}

Spasm of transplanted vessels can occur after surgical manipulation or intimal injury, which may occur during or after surgery. The surgeon can use topical vasodilators (papaverine, verapamil, lidocaine) to reduce this phenomenon ${ }^{6}$. 


\section{Sympathetic blockade}

Use of local anesthetics (epidural, brachial plexus, pleural) in peri- and post-operative periods produces sympathetic blockade and therefore vasodilation. There have been concerns about the transplanted vessels, sympathetically denervated and unable to dilate after lumbar epidural block, resulting in reduced steal effect reducing flap BF. However, if hypotension is corrected by sympathetic block, flap BF improves as a result of increased artery $\mathrm{BF}$ in the receptor tissue ${ }^{6}$.

\section{ANESTHETIC APPROACH}

\section{Preoperative}

All patients scheduled for this surgery must be evaluated before surgery. Chronological age alone is neither a contraindication for surgery nor a risk for postoperative morbidity and flap failure ${ }^{8,9}$. A preoperative high ASA status is associated with higher postoperative morbidity 10,11 . Patients with head and neck cancer are often elderly, smokers, with a history of alcoholism and, therefore, associated with comorbidity (heart and lung), sometimes associated with poor nutritional status. These patients often have an altered anatomy, either by the tumor or as a result of radio/chemotherapy, which may anticipate the possibility of a difficult airway. Previous radiotherapy increases the postoperative complications of the wound and is associated with flap failure if the receiving site was previously irradiated ${ }^{12,13}$.

In the preoperative period, it is also important to rule out cardiac ischemia. The incidence of perioperative myocardial infarction in one study was $3.6 \%$. Interesting is the fact that the flap remained intact during the emerging coronary revascularization ${ }^{14}$.

There is no evidence of increased flap failure or thrombosis in smokers. However, there is evidence that in transverse rectus abdominis musculocutaneous (TRAM) flap for breast reconstruction, smokers have higher incidence of skin necrosis, necrosis at the site of abdominal pain, hernias, and wound infection ${ }^{15}$. Smoking is a contraindication for TRAM flap breast reconstruction due to the high incidence of complications ${ }^{16}$. Patients should be advised to stop smoking at least three weeks before surgery, thereby reducing the incidence of failure of reconstructive surgery of head and neck ${ }^{17}$.

Diabetes is not a contraindication to this surgical technique, as it is not associated with increased incidence of thrombosis or flap failure ${ }^{12}$. However, some authors found that hyperglycemia (acute and chronic) is associated with vascular leakage and more likely to cause tissue edema ${ }^{18}$. This edema may increase the extravascular pressure, with negative effect on vascular diameter of flap. Thus, close monitoring of blood glucose is essential to minimize metabolic disorders and optimize the flap blood flow.

Obesity is a risk factor for major complications of this surgery. A retrospective analysis over a period of 10 years involving TRAM flaps showed a significant increase in the in- cidence of flap failure, hernia, and necrosis in patients with $\mathrm{BMI}>30{ }^{19}$. These patients also have a higher incidence of medical complications.

The recommended preoperative investigation is blood count, coagulation, ionogram and renal function, blood glucose, chest X-ray, ECG. Other tests (e.g., echocardiography, pulmonary function tests, blood gas, or other) should be considered if the associated pathology justifies them. All patients should be typed and have reserves of blood ${ }^{4}$.

\section{Perioperative period}

The basic targets of anesthesia are to provide adequate perfusion of transplanted tissue and minimize any morbidity associated with prolonged surgery/anesthesia ${ }^{7}$.

The basic requirements for microanastomosed flap are to ensure hyperdynamic circulation and maintain normothermia.

\section{Warming}

Intuitively, it makes sense to keep these normothermic patients with active warming to prevent increased viscosity and vasoconstriction. Normothermia maintenance may be difficult with large areas exposed for prolonged periods, associated with fluid and blood loss. Furthermore, anesthesia changes the thermoregulatory mechanisms.

In the ' 80 s, some studies of animals have confirmed the deleterious effects of hypothermia on viscosity and flow of pedicle and free flaps ${ }^{20}$. There are few studies of the effects of hypothermia on flap blood flow in humans, perhaps because it may be unethical. However, there are reports of flaps that survived hypothermia associated with cardiac bypass ${ }^{14}$.

Central and peripheral temperature must be monitored and the ideal difference $(\Delta t)$ between them should be less than $1^{\circ} \mathrm{C}$. The $(\Delta \mathrm{t})$ can reflect the volemic status of a patient ${ }^{4}$.

Active heating (solution heaters, blanket with forced hot air) should be initiated as soon as possible and cover the greatest possible extent. If possible, the room temperature must be increased to $22^{\circ}-24^{\circ} \mathrm{C}$, a temperature that reduces heat loss from the patient and is not uncomfortable for the surgical team $^{6}$.

\section{Positioning}

Preoperative preparation and patient positioning can be time consuming and it is important to prevent hypothermia during this phase of exposure. Patient positioning deserves meticulous attention to possible pressure points in order to avoid problems, such as neuropathy (damage to peripheral nerves) and pressure ulcers. Gel pads are particularly useful for areas of greatest risk. The positioning may be readjusted several times during surgery, requiring a reassessment of pressure zones ${ }^{8}$. The eyes should be protected to reduce the incidence of corneal ulcers and dryness. 
Prophylaxis of thromboembolic events should be given to all patients (low molecular weight heparin, preoperatively). The use of pneumatic compression stockings is recommended, and some authors even recommend the passive mobilization of the limbs several times during surgery 4 .

\section{Access and monitoring}

Because large mobilizations of fluids may occur during surgery, catheterization is essential for good venous (large caliber) access. The location must be discussed with surgeon, as it can influence the harvesting place.

In addition to basic monitoring, invasive arterial pressure (AP) monitoring (always with free flap) is recommended in these patients. This allows not only precise and continuous monitoring of $\mathrm{AP}$, as well as serial blood gases and hematocrit calculation.

Central venous pressure monitoring reflects the cardiac filling pressures and can be used for cardiac output management. It is useful if there is massive blood loss or the patient has poor peripheral access, but it is not recommended as routine. Moreover, in head and neck surgery, direct access to central veins may be difficult or even impossible ${ }^{7}$.

Central temperature monitoring (via nasopharyngeal or rectal/bladder tube) is essential when performing active warming. Peripheral temperature must also be measured, as a decrease in skin temperature may reflect hypovolemia and vasoconstriction. A difference of less than $2^{\circ} \mathrm{C}$ between central and peripheral temperature indicates a warm and wellfilled patient ${ }^{6}$.

Urine output is another indicator of vascular filling. Tube placement allows not only the monitoring but also the prevention of bladder distension. An output from 1 to $2 \mathrm{~mL} . \mathrm{kg}^{-1}$ should be kept in peri- and postoperative periods through an appropriate fluid therapy. Diuretics should be avoided, as volume depletion compromise the flap success ${ }^{6}$.

Gastric tube should be placed to reduce gastric distension and, therefore, nausea and vomiting after surgery.

\section{The technique}

If appropriate, regional block may be performed, preferably for harvesting the flap, taking advantage of the sympathetic block ${ }^{6}$. A balanced technique may be used, with adequate analgesia to reduce the stress response and catecholamine release. The use of nitrous oxide should be avoided, especially in long surgeries because it is associated with gastric distension, nausea and vomiting after surgery. Moreover, there appears to be a greater risk of postoperative cardiac ischemia ${ }^{21,22}$. Sevoflurane and desflurane are possible choices because both agents provide cardiovascular stability associated with rapid awakening after long surgeries. The effects of different anesthetics on free flaps blood flow are not properly understood ${ }^{5}$. Furthermore, little is known about how anesthetics affect microvascular parameters related to fluid distribution ${ }^{23}$. It has been shown that sevoflurane, compared with intravenous anesthetics such as propofol, may have beneficial effects on microcirculation, reducing plasma leakage into interstitial space and, therefore, decreasing the edema ${ }^{24}$. Some authors also report that it may have a protective effect on endothelial cells against ischemia-reperfusion ${ }^{25}$. The use of remifentanil provides adequate perioperative analgesia, rapid control of blood pressure, vasodilation, and reduces the need for muscle relaxant perioperative, allowing excellent conditions in microvascular surgery ${ }^{2}$. The use of relaxants may be necessary for surgical reasons (e.g., to reduce muscle twitch during vascular pedicle dissection). The use propofol and remifentanil target-controlled infusion (TCI) is also another popular technique ${ }^{7}$. Further studies are needed to compare inhaled and intravenous anesthesia in microvascular surgery ${ }^{2}$.

The patient should be ventilated to achieve normocapnia ${ }^{6}$. Hypocapnia increases peripheral vascular resistance and decreases cardiac output, while hypercapnia causes sympathetic stimulation and reduces erythrocyte deformity. Hyperoxia causes vasoconstriction ${ }^{26,27}$. The increase in $\mathrm{PaO}_{2}$ is followed by a decrease in tissue perfusion as a result of vasoconstriction, leading to poor distribution of microcirculation infusion ${ }^{28}$. When the microscope is used for preparation of anastomosis in chest or abdomen, the tidal volume should be reduced to minimize movements. The respiratory rate must be increased to maintain the minute volume.

Controlled hypotension is often indicated during initial dissection, especially in extensive surgery of malignant tumors with node dissection or free musculocutaneous flaps of large dimensions $^{2}$.

When flap is reperfused, the patient should be normothermic, well filled, and sympathetically blocked with high cardiac output 6 .

\section{Fluid therapy}

For appropriated maintenance of perfusion pressure in transplanted flap, hyperdynamic circulation is required with high cardiac output, pulse pressure, and peripheral vasodilation. An adequate blood pressure with vasodilatation promotes good flap perfusion by increasing the regional blood flow, enhancing the microvascular patency and maintaining the "fluidity" of blood in the microcirculation. By increasing cardiac filling pressures, cardiac output is increased achieving muscle and cutaneous vasodilation ${ }^{4}$.

Normovolemic or hypervolemic hemodilution demonstrated (experimentally and clinically) to improve the chance of tissue success (survival) with compromised circulation. Most patients tolerate hematocrit falls to $18-20 \%$, even if the delivery of $\mathrm{O}_{2}$ to tissues is probably optimal for hematocrit of $30 \%$. On the other hand, a very low hematocrit is associated with a prolonged bleeding time. Even if CVP measurement does not provide accurate information on peripheral circulation, a "target" CVP of $3-5 \mathrm{~cm} \mathrm{H}_{2} \mathrm{O}$ above the baseline value is recommended. More important than a value in itself is the tendency 
of CVP; thus, other relevant information such as urine output and $\Delta \mathrm{t}$ (difference between central and peripheral temperature) should be also considered ${ }^{4}$.

Traditionally, hypervolemic hemodilution has been used during anesthesia for this type of surgery ${ }^{29}$. Although theoretically attractive due to the consequent reduction in viscosity, there is no clinical evidence that it is beneficial. The free flaps are subject to interstitial edema, as they do not have lymphatic drainage and, thus, excessive fluid administration can be deleterious ${ }^{7}$. On the other hand, patients with documented ischemic heart disease or ventricular dysfunction may not tolerate a volume overload, and to perform a hemodilution is probably preferable. Fluid administration should be cautious and guided by signs of ischemia and hypoperfusion (ST depression, decreased urine output, increased serum lactate, increased $\Delta t$ ). Perhaps patients with significant cardiac disease are better "served" with a surgery less ambitious, though aesthetically less satisfactory. Left ventricular failure guarantees flap failure ${ }^{4}$.

Maintaining an adequate mean arterial pressure and cardiac output is crucial. The combination of crystalloid and colloids is generally appropriated, guided by urinary output of at least $0.5 \mathrm{~mL} \cdot \mathrm{kg}^{-1} \cdot \mathrm{h}^{-1}$.

It seems prudent to limit the use of crystalloids only to the replacement of maintenance needs ${ }^{7}$, noting that excessive use can cause flap edema.

Synthetic colloids have the advantage of being readily available, stable, relatively inexpensive, and with no risk of transmitting infectious diseases.

Gelatins have a short half-life and may lead to postoperative hypovolemia.

Dextrans as plasma substitutes were more effective than gelatins or large volumes of crystalloids, and seem to have beneficial effects on microcirculation. Its antithrombotic effects by reducing platelet adhesion and depression of factor VIII activity represent an advantage in terms of thromboprophylaxis, but limit the amount administered during a major loss of blood ${ }^{4}$. In addition, its benefit in terms of flap survival has not been clinically demonstrated yet ${ }^{30}$.

Hydroxyethyl starches have characteristics that may be beneficial for microvascular surgery. They are good plasma expanders, have low incidence of anaphylactic reactions, and may reduce reperfusion injury and hyperpermeability after temporary ischemia. Its disadvantages include prolongation of bleeding time (if used in large quantities) and high incidence of postoperative pruritus.

Hypertonic saline solutions have been the subject of some recent interest ${ }^{4}$. Besides being plasma expanders, they have cardiovascular benefits (increase myocardial contractility, decrease afterload, and increased preload). They trigger a high transcapillary osmotic gradient, which forces fluid out of microvascular endothelial and red blood cells, resulting in vasodilation arterioles, reopening of occluded capillaries, and reduced reperfusion injury. Its duration of action is 15-20 minutes, but may be prolonged to $30-60$ min by adding a colloid.
Other disadvantages are hypernatremia, hypokalemia, and hypovolemia intracellular, although these do not seem to be clinically problematic.

Blood loss can be considerable during extensive and long surgeries. A "liberal" transfusion policy is associated with increased morbidity and mortality ${ }^{31}$. Blood transfusion is recommended if hemoglobin falls to values below 7-8 g.dL-1 4,8. This technique was successfully performed in Jehovah's Witness patients without increased number of complications ${ }^{32}$. If bleeding is significant, administration of platelets and coagulation factors may be necessary ${ }^{4}$.

\section{Tension control / vasoactive agents}

As mentioned above, controlled hypotension is recommended during dissection to improve surgical conditions and reduce blood loss. Other steps include patient positioning to improve venous drainage or infiltration with local anesthetics. Blood pressure can be controlled in many ways, with flexible and rapidly reversible combinations (e.g., TIVA with propofol and remifentanil). Several vasoactive agents were investigated to determine the effect on flaps (either pedicle or free) and to improve the success. Pedicled flaps maintain innervation intact, while free flaps are denervated; therefore, it is difficult to predict the effect of these drugs, particularly in the latter ${ }^{7}$.

Vasodilators are theoretically attractive, but the reduction in mean arterial pressure (MAP) seems to exceed the benefits of increased vessel diameter. Animal studies of sodium nitroprusside showed marked reduction of MAP and BF in flap and may cause reflex vasoconstriction when infusion is interrupted ${ }^{33}$. Intravenous milrinone was investigated in human free flaps, but there was no significant change in the outcome ${ }^{34}$. Topical application of vasodilator agents, such as verapamil, nicardipine, papaverine, lidocaine, and $\mathrm{PgE} 1$, are sometimes used by surgeons, and some animal and human data indicate that these agents can help prevent vasoespam ${ }^{35,36}$.

Beta-blockers can cause peripheral vasoconstriction and therefore its use (especially taking advantage of its potential cardiac benefit) must take into account the risk/benefit ${ }^{7}$.

Catecholamines are generally avoided, although there is little evidence that its systemic administration has adverse effect on flap blood flow. Hypotension is usually secondary to the fluid loss or vasodilation and should be treated with fluid therapy.

Animal experiments suggest that the effect of vasopressors on pedicle and free flaps is different. Phenylephrine, predominantly a vasoconstrictor, increases MAP without significant changes in free flaps BF in normovolemic pigs, but with a significant increase in hypotensive pigs with vasodilation by epidural blockade ${ }^{33,37}$. In pedicle flaps, phenylephrine decreases BF, whereas small doses of adrenaline (in the same study) produced a significant increase in $\mathrm{BF}{ }^{38}$. Therefore, phenylephrine should be avoided, if possible, in pedicle flaps ${ }^{7}$.

Studies of dobutamine and dopamine in pedicle flaps used for breast reconstruction showed increased BF in the first case and no change in the second ${ }^{39}$. The use of dobutamine 
increases cardiac output with systemic vasodilation and, therefore, its use should only be considered in combination with good intravenous filling. It should also be taken into account that the associated cutaneous vasodilation will lead to greater heat loss.

\section{Coagulation and thrombolysis}

In a large study of free flap surgery, the subcutaneous administration of heparin was associated with significant improvement in flap survival ${ }^{12}$. However, perioperative anticoagulation with intravenous heparin showed no clinical benefit 40 . Aspirin seems to be as effective as subcutaneous heparin in free flap surgery ${ }^{41}$. Clopidogrel reduces microvascular thrombosis in rats, but has not been used in large numbers in clinical practice ${ }^{42}$. Thrombolytic agents (such as streptokinase and urokinase) are administered directly into the thrombosed vessels by the surgeon ${ }^{43}$.

Administration of intravenous heparin (2,500-5,000 U) before flap harvesting is not consensual. Vessel lumen is usually irrigated with heparinized solution (5,000 U: $500 \mathrm{ml} \mathrm{NS}$ ). Small doses of heparin do not appear to increase the risk of postoperative hematoma and hemorrhage ${ }^{1}$.

\section{Other drugs}

Antibiotic prophylaxis should be initiated before surgery. The use of antiedema therapy must be balanced, particularly in head and neck surgery. Dexamethasone has the additional advantage of being antiemetic.

\section{Postoperative period}

Most patients can be extubated at the end of surgery despite the long duration. In cases of head and neck tumor, where edema may be a problem, a period of mechanical ventilation after elective surgery can be considered. In such cases, the risk of lowering blood pressure and, in turn, flap perfusion secondary to sedation must be weighed.

Patient awakening and extubation can be a challenge even for experienced anesthesiologists. It is desirable to have an awake and cooperative patient, but it is also important to avoid large pressure variations associated with cough and agitation. This is particularly important in head and neck surgery and is vital to ensure an optimal analgesia prior to anesthesia discontinuation ${ }^{7}$.

\section{Techniques used to reduce the risk of major changes in AP during extubation}

- Allows the patient to wake up gradually and breathe spontaneously with deflated cuff.
- Change endotracheal tube to laryngeal mask before reversal of neuromuscular blockade.

- Lidocaine (0.5 mg. $\mathrm{kg}^{-1}$ ) EV (reduces coughing).

- Small titrated bolus of $\beta$-blockers (e.g., esmolol).

Recovery of consciousness should be painless. Analgesia should be multimodal and maintained in the postoperative period. NSAIDs should be avoided at an early stage, if possible, given the risk of perioperative bleeding and hematoma formation. Regional anesthesia, particularly for the pain site, may be beneficial. When opioids are prescribed, a prophylactic antiemetic should be associated 4 .

It is essential that all measures taken to ensure adequate perfusion pressure during surgery be continued in the postoperative period; therefore, medical care and vigilance should be kept at units prepared for such conditions.

Patients must be kept normothermic. Postoperative shivering should be prevented and promptly treated, as it more than doubles the $\mathrm{O}_{2}$ consumption, increases the circulating catecholamines, and causes peripheral vasoconstriction. It has also been shown to cause a marked reduction in flap BF. Treatment should be made with external heating associated with small intravenous doses of meperidine $(10-20 \mathrm{mg})$. Recently, one study demonstrated that tramadol could be even more effective ${ }^{44}$. Other drugs such as chlorpromazine (2.5-5 mg) or clonidine (100-150 $\mu \mathrm{g}$ ) have been also used. Yet, flap BF can take about an hour to return to normal.

Blood pressure should be closely monitored, and hypovolemia should be treated. Fluid therapy should allow urine output of $0.5-1 \mathrm{~mL} . \mathrm{kg}^{-1} \mathrm{~h}^{-1}$. Vasopressors are generally not necessary; however, in ventilated and sedated patients they may be necessary to maintain appropriate MAP ${ }^{7}$.

There is no consensus on recommended protocol for postoperative anticoagulation. Aspirin and low molecular weight heparin seems to be an appropriate choice of anticoagulant agents in the postoperative period of head and neck free flap reconstruction surgery ${ }^{41}$.

Failure rate is approximately $4 \%$ with a rate of re-exploration of about $10 \%{ }^{12}$. A retrospective study of 1,142 free flaps had a re-exploration rate of $9.9 \%$, with $82 \%$ of these flaps presenting circulatory problems within 24 hours ${ }^{45}$. The most frequent causes are inadequate surgical anastomosis, arterial thrombosis and spasm, and insufficient venous drainage. Other causes include edema due to excessive hemodilution, manipulation trauma (e.g., dressings), and prolonged ischemia time ${ }^{7}$.

Flap clinical monitoring (color, capillary return, temperature) has limited value. Laser Doppler flowmetry is probably the best available method for flap noninvasive monitoring ${ }^{46}$. Despite the development of sophisticated equipment for flap monitoring, decisions about its "welfare" status are usually based on simple clinical observations. A pale and cold flap usually indicates arterial thrombosis, while a congested flap usually indicates venous obstruction. In both cases, re-exploration is urgently necessary, as early re-exploration accounts for $75 \%$ of flap "recovery" cases. 


\section{Postoperative care ${ }^{4}$}

- Normothermia $\left(\Delta t<1^{\circ} \mathrm{C}\right)$.

- Hyperdynamic circulation - high cardiac output and low systemic vascular resistance.

- Normal systolic blood pressure (> $100 \mathrm{~mm} \mathrm{Hg}$ ).

- Hematocrit $30 \%$ (monitoring in the first $24 \mathrm{~h}$ qid).

- Urine output $>1 \mathrm{~mL} \cdot \mathrm{kg}^{-1} \cdot \mathrm{h}^{-1}$.

- $\mathrm{SpO}_{2}>94 \%\left(\mathrm{O}_{2}\right.$ in the first $\left.24 \mathrm{~h}\right)$.

- Effective analgesia.

- Periodic monitoring of flap and continuous monitoring of flap blood flow (Doppler).

\section{CONCLUSION}

Anesthesia for microvascular flap surgery is a challenge. The role of the anesthesiologist includes the optimization of the physiological conditions for flap survival without increasing non-surgical morbidity. Close communication and knowledge of the steps as well as of the pathophysiology are necessary to ensure a favorable outcome. 


\section{REFERENCES}

1. Nahabedian M - Flaps, free tissue transfer. Medscape eMedecine, 2008.

2. Hagau N, Longrois $\mathrm{D}$ - Anesthesia for free vascularised tissue transfer. Microsurgery, 2009;29:161-167.

3. Hidalgo DA, Jones CS - The role of emergent exploration in free tissue transfer. A review of 150 consecutive cases. Plast Reconstr Surg, 1990;86:492-499.

4. Adams J, Charlton $\mathrm{P}$ - Anesthesia for microvascular free tissue transfer. Br J Anaesth (CEPD Reviews), 2003;3:33-37.

5. Sigurdsson $\mathrm{GH}$, Thomson $\mathrm{D}$ - Anesthesia and microvascular surgery: Clinical practice and research. Eur J Anaesthesiol, 1995;12:101-122.

6. Quinlan J - Anaesthesia for reconstrutive surgery. Anaesth Intensive Care, 2006; 7: 31-35.

7. Pushparaj S, Boyce H, Chisholm D - Curr Anaesth Crit Care, 2009;20:18-21.

8. Malata CM, Cooter RD, Batchelor AG et al - Microvascular free-tissue transfers in elderly patients: the Leeds experience. Plast Reconstr Surg, 1996;98:1234-1241.

9. Ozkan O, Ozgentas HE, Islamoglu $\mathrm{K}$ et al - Experiences with microsurgical tissue transfers in elderly patients. Microsurgery, 2005;25:390395 
10. Serletti JM, Higgins JP, Moran S et al - Factors affecting outcome in free tissue transfer in the elderly. Plast Reconstr Surg, 2000;106:6670 .

11. Coskunfirat OK, Chen HC, Spanio S et al - The safety of microvascular free tissue transfer in the elderly population. Plast Reconstr Surg, 2005;115:771-775.

12. Khouri R, Cooley BC, Kunselman AR et al - A prospective study of microvascular free flap surgery and outcome. Plast Reconstr Surg, 1998;102:711-721.

13. Klug C, Berzaczy D, Reinbacher $\mathrm{H}$ et al - Influence of previous radiotherapy on free tissue transfer in the head and neck region: evaluation of 455 cases. Laryngosope, 2006;116:1162-1167.

14. Chiang S, Cohen B, Blackwell K - Myocardial infarction after microvascular head and neck reconstruction. Laryngoscope, 2002;112:18491852.

15. Chang DW, Reece GP, Wang B et al - Effect of smoking on complications in patients undergoing free TRAM flap breast reconstruction. Plast Reconstr Surg, 2000;105:2374-2380.

16. Spear SL, Ducic I, Cuoco F et al - The effect of smoking on flap and donor site complications in pedicled TRAM breast reconstruction. Plast Reconstr Surg, 2005;116:1873-1880.

17. Kuri $\mathrm{M}$, Nakagawa $\mathrm{M}$, Tanaka $\mathrm{H}$ et al - Determination of the duration of perioperative smoking cessation to improve wound healing after head and neck surgery. Anesthesiology, 2005;102:892-896.

18. Scalia R, Gong Y, Berzins B et al - Hyperglycemia is a major determinant of albumin permeability in diabetic microcirculation. The role of I-Calpain. Diabetes, 2007;56:1842-1849.

19. Chang DW, Wang B, Robb GL et al - Effect of obesity on flap and donor-site complications in free transverse rectus abdominis myocutaneous flap breast reconstruction. Plast Reconstr Surg, 2000;105:16401648.

20. Awwad AM, White RJ, Webster MH et al - The effect of temperature on blood flow in island and free skin flaps: an experimental study. $\mathrm{Br} \mathrm{J}$ Plast Surg, 1983;36:373-382.

21. Myles PS, Leslie K, Chan MT et al - Avoidance of nitrous oxide for patients undergoing major surgery: a randomized controlled trial. Anesthesiology, 2007;107:221-231.

22. Myles PS, Chan MT, Leslie K et al - Effect of nitrous oxide on plasma homocysteine and folate in patients undergoing major surgery. $\mathrm{Br} \mathrm{J}$ Anaesth, 2008;100:780-786.

23. Hahn RG - Microvascular changes and anesthesia. Acta Anaesthesiol Scand, 2002;46:479-480.

24. Bruegger D, Bauer A, Finsterer $U$ et al - Microvascular changes during anesthesia: Sevoflurane compared with propofol. Acta Anaesthesiol Scand, 2002;46:481-487.

25. Lucchinetti $\mathrm{E}$, Ambrosio $\mathrm{S}$, Aguirre $\mathrm{J}$ et al - Sevoflurane inhalation at sedative concentrations provides endothelial protection against ischemia-reperfusion injury in humans. Anesthesiology 2007;106:262268.

26. Bertuglia S, Colantuoni A, Coppini G et al - Hypoxia- or hyperoxiainduced changes in arteriolar vasomotion in skeletal muscle microcirculation. Am J Physiol Heart Circ Physiol, 1991;260:H362-H372.

27. Messina EJ, Sun D, Koller A et al - Increases in oxygen tension evoke arteriolar constriction by inhibiting endothelial prostaglandin synthesis. Microvasc Res, 1994;48:151-160.

28. Tsai AG, Cabrales P, Winslow RM et al - Microvascular oxygen distribution in awake hamster window chamber model during hyperoxia. Am J Physiol Heart Circ Physiol, 2003;285:H1537- H1545.

29. Sigurdsson GH - Perioperative fluid management in microvascular surgery. J Reconstr Microsurg, 1995;11:57-65.

30. Pohlenz $\mathrm{P}$, Blessmann $\mathrm{M}$, Heiland $\mathrm{M}$ et al - Postoperative complications in 202 cases of microvascular head and neck reconstruction. $J$ Craniomaxillofac Surg, 2007;35:311-315.

31. Hébert PC, Wells G, Blajchman MA et al - A multicenter, randomized, controlled clinical trial of transfusion requirements in critical care. Transfusion Requirements in Critical Care Canadian Critical Care Trials. N Engl J Med, 1999;11;340:409-417.

32. Skoner JM, Wax MK - Microvascular free-tissue transfer for head and neck reconstruction in Jehovah's Witness patients. Head Neck, 2008;30:455-460.
33. Banic A, Krejci V, Erni D et al - Effects of sodium nitroprusside and phenylephrine on blood flow in free musculocutaneous flaps during general anesthesia. Anesthesiology, 1999;90:147-155.

34. Jones SJ, Scott DA, Watson $\mathrm{R}$ et al - Milrinone does not improve free flap survival in microvascular surgery. Anaesth Intensive Care, 2007;35:720-725.

35. Weinzweig N, Lukash F - Topical and systemic calcium channel blockers in the prevention and treatment of microvascular spasm in a rat epigastric island skin flap model. J Ann Plast Surg, 1999;42:320326.

36. Rodrı'guez Vegas JM, Ruiz Alonso ME, Tera'n Saavedra PP - PGE-1 in replantation and free tissue transfer: early preliminary experience. Microsurgery, 2007;27:395-397.

37. Banic A, Krejci V, Erni D et al - Effects of extradural anesthesia on microcirculatory blood flow in free latissimus dorsi musculocutaneous flaps in pigs. Plast Reconstr Surg, 1997;100:945-955.

38. Massey MF, Gupta DK - The effects of systemic phenylephrine and epinephrine on pedicle artery and microvascular perfusion in a pig model of myoadipocutaneous rotational flaps. Plast Reconstr Surg, 2007;120:1289-1299.

39. Suominen S, Svartling N, Silvasti M et al - The effect of intravenous dopamine and dobutamine on blood circulation during amicrovascular TRAM flap operation. Ann Plast Surg, 2004;53:425-431.

40. Chen CM, Ashjian P, Disa JJ et al - Is the use of intraoperative heparin safe? Plast Reconstr Surg, 2008;121:49e-53e.

41. Chien W, Varvares MA, Hadlock T et al - Effects of aspirin and lowdose heparin in head and neck reconstruction using microvascular free flaps. Laryngoscope, 2005;115:973-976.

42. Moore MG, Deschler DG - Clopidogrel (Plavix) reduces the rate of thrombosis in the rat tuck model for microvenous anastomosis. Otolaryngol Head Neck Surg, 2007;136:573-576.

43. Panchapakesan V, Addison P, Beausang $E$ et al - Role of thrombolysis in free-flap salvage. J Reconstr Microsurg, 2003;19:523-530.

44. Bhatnagar S, Saxena A, Kannan TR et al - Tramadol for postoperative shivering: a double-blind comparison with pethidine. Anaesth Intensive Care, 2001;29:149-154.

45. Chen KT, Mardini S, Chuang DC et al - Timing of presentation of the first signs of vascular compromise dictates the salvage outcome of free flap transfers. Plast Reconstr Surg, 2007;120:187-195.

46. Rosenberg JJ, Fornage BD, Chevray PM - Monitoring buried free flaps: limitations of the implantable Doppler and use of color duplex sonography as a confirmatory test. Plast Reconstr Surg 2006;118:109113. 